DOI: $10.5216 /$ cab.v14i4.8581

\title{
ESTUDO ANATOMOPATOLÓGICO EM TECIDOS CONDENADOS PELO SERVIÇO DE INSPEÇÃO FEDERAL (SIF) POR SUSPEITA DE TUBERCULOSE
}

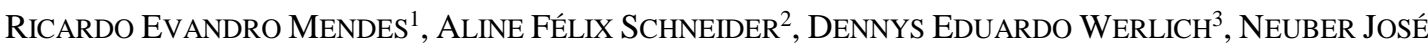 \\ LUCCA $^{4}$, MARINA PAULA LORENZETT ${ }^{4}$, CÉlSO PILATI ${ }^{5}$
}

\author{
${ }^{1}$ Doutor, Professor de Patologia Veterinária, Instituto Federal Catarinense, Concórdia, SC, Brasil. \\ ricardo.mendes@ifc-concordia.edu.br \\ ${ }^{2}$ Mestre, Professora do Centro Universitário Barriga Verde, Orleans, SC, Brasil. \\ ${ }^{3}$ Mestre, Médico Veterinário do Ministério da Agricultura, Pecuária e Abastecimento, Brasil. \\ ${ }^{4}$ Acadêmico do curso de Medicina Veterinária do Instituto Federal Catarinense, Concórdia, SC, Brasil. \\ ${ }^{5}$ Doutor, Professor de Histologia Veterinária, Universidade do Estado de Santa Catarina, Lages, SC, Brasil.
}

\section{RESUMO}

A metodologia utilizada pela inspeção animal na linha de abate tem gerado controvérsias entre o que deve ser condenado e liberado ao consumo. Acredita-se que órgãos e carcaças estejam sendo condenados por tuberculose sem apresentarem lesão microscópica compatível com tal patologia. O objetivo deste trabalho foi identificar as lesões microscópicas encontradas em amostras de linfonodos condenados por tuberculose pelo SIF (Serviço de Inspeção Federal). Foram coletadas 61 amostras condenadas pelo SIF por suspeita de tuberculose. Os linfonodos foram fixados em formalina tamponada $10 \%$, recortados, processados rotineiramente e incluídos em parafina. Na avaliação realizada pela coloração de Hematoxilina e Eosina (H\&E), observaram-se 55 granulomas tuberculóides e três granulomas actinomicóides, um linfonodo apresentando cristais com leve reação inflamatória e dois hiperplasia linfóide. Concluímos, portanto, que o índice de acerto de condenação de lesões de linfonodos por tuberculose foi satisfatório, entretanto poderia ser melhorado.

PALAVRAS-CHAVE: bovino; inspeção; Mycobacterium bovis; SIF; tuberculose.

\section{ANATOMOPATHOLOGICAL STUDY IN CONDEMNED TISSUES UNDER SUSPICIOUS OF TUBERCULOSIS BY THE BRAZILIAN FOOD SAFETY AND INSPECTION SERVICE}

\section{ABSTRACT}

The methodology used during the Animal Standard Meat Inspection (SIS) has been controversial in the decision to condemn or approve materials for human consumption. The aim of this study was to identify the microscopic lesions found in lymph node tissues condemned for tuberculosis by the Brazilian SIS. Sixty-one condemned lymph nodes were collected, fixed in buffered formalin $10 \%$ and submitted to histological processing. By evaluating the condemned tissues with $\mathrm{H} \& \mathrm{E}$ stain, 55 tuberculoid granuloma were found, as well as three 
actinomycosis granuloma, 2 presenting lymphoid hyperplasia and 1 crystal deposition. The misdiagnosis rate in the samples condemned due to tuberculosis was satisfactory, however it can be improved.

KEYWORDS: cattle; meat inspection; Mycobacterium bovis; tuberculosis.

\section{INTRODUÇÃO}

A presença de tuberculose em produtos de origem animal para consumo humano é um problema de saúde publica. A grande maioria dos países conta, atualmente, com programas de erradicação, alguns vigentes desde o inicio do século passado. $\mathrm{O}$ número de casos de humanos infectados pela tuberculose tem sofrido um crescente aumento nos últimos anos, especialmente devido à sua associação com o vírus da imunodeficiência adquirida humana (SALIHU et al., 2001; SOBORG et al., 2001; CEGIELSKI et al., 2002; RAVIGLIONE \& PIO, 2002; PAIXÃO \& GONTIJO, 2007; WHO, 2008).

Apesar dos esforços intensivos nas últimas décadas, a tuberculose bovina ainda é um problema global (POLLOCK et al., 2005). O impacto da doença varia de país a país, e tem uma influência negativa no comércio de produtos cárnicos (BIET et al., 2005). Nos países em que a doença não está controlada, Mycobacterium bovis ainda permanece como importante agente patógeno humano. Com sintomatologia indistinguível da causada pelo Mycobacteriun tuberculosis, representa entre 10 a $15 \%$ do total de casos de tuberculose em humanos (ASHFORD et al., 2001; BIET et al., 2005; DE LA RUA-DOMENECH, 2006; THOEN et al., 2006). Entretanto, como, para efeitos de notificação, muitos países não distinguem entre os diversos tipos de agentes etiológicos da tuberculose, esse valor pode estar subestimado (EU, 2003).

No Brasil, a prevalência da doença em bovinos foi estimada em 1,3\% de 1989 a 1998. O exame post-mortem realizado pelo serviço de inspeção aporta apenas um diagnóstico presuntivo, pois se constitui somente de uma análise macroscópica dos achados, condenando lesões caseosas compatíveis com tuberculose (BRASIL, 2001), de acordo com a avaliação dos inspetores oficiais. Esse diagnóstico pode ser confundido com o de outros processos inflamatórios granulomatosos, como infecções por Corynebacterium pyogenes, actinomicoses, coccidiomicoses, actinobacilose, lesões causadas por larvas de parasitos e lesões carcinomatosas (CURCIO et al., 2002).

Em um estudo comparativo entre diversos métodos de diagnóstico, VARELLO et al. (2008) concluíram que a análise histopatológica é o teste com maior sensibilidade $(93,4 \%)$ e especificidade $(92,3 \%)$ para o diagnóstico da tuberculose, além de sua especial utilidade para uma maior rapidez de diagnóstico.

No Rio Grande do Sul, em frigoríficos com SIF, a condenação por lesões similares à tuberculose foi de 0,95\% em 1980, 0,42\% em 1988, 0,22\% em 1992 e 0,36\% em 1996 (ANDRADE et al., 1991). BAPTISTA et al. (2004) identificaram a ocorrência de $0,92 \%$ de condenação por tuberculose no Sistema de Inspeção Federal (SIF) mineiro. Diversos trabalhos relatam uma prevalência de tuberculose diagnosticada em abatedouro entre $0,12 \%$ e $16 \%$. Entretanto, somente em $29,4 \%$ a $55 \%$ desses casos foi confirmada sua positividade por alguma técnica complementar (HERNANDEZ et al., 1997; MILIAN-SUAZO et al., 2000; TEKLUL et al., 2004; ARAÚJO et al., 2005).

O diagnóstico molecular ou por cultura bacteriana de material procedente de abatedouros apresenta muitos inconvenientes: alto custo financeiro, longo tempo para isolamento, reduzido número de laboratórios de referência no país e, em caso de resultado negativo, não gera um diagnóstico definitivo. Portanto, a utilização rotineira desses tipos de diagnóstico em um programa de erradicação de tuberculose enfrenta inúmeras dificuldades. Entretanto, o pagamento de prêmios e/ou indenizações para os animais positivos, à semelhança da metodologia utilizada nos Estados Unidos, que podem chegar a U\$ 1000 por animal (KANEENE et al., 2006), incentivaria e facilitaria a sua adoção. Ainda, há a constante necessidade de aporte de dinheiro público que permita um treinamento contínuo dos inspetores, melhorando a sua taxa de acerto.

O objetivo deste trabalho foi confirmar se linfonodos de carcaças condenadas por tuberculose macroscopicamente por profissionais do SIF apresentam lesões microscópicas compatíveis com esta patologia.

\section{MATERIAL E MÉTODOS}

Os linfonodos analisados foram coletados, em frigorífico com Inspeção Federal, de bovinos abatidos comercialmente durante todo o ano de 2006. Neste estabelecimento, $96 \%$ dos animais abatidos 
são de raça zebuína ou cruzados e com idade ao abate de até 30 meses. O estabelecimento é de porte grande, abatendo em média 220.000 animais anualmente. $\mathrm{O}$ material foi dividido em dois grupos experimentais, sendo o Grupo 1 constituído dos linfonodos suspeitos de tuberculose por um inspetor do SIF e o grupo 2 constituído de linfonodos normais.

Para o grupo 1 foram selecionadas 61 amostras condenadas e consideradas impróprias para o consumo pelo Serviço de Inspeção Federal (SIF), colhidas à medida que foram rejeitadas na linha de Inspeção. Foram coletadas principalmente amostras de linfonodos submandibular, pré-escapular e mediastínico que apresentaram lesão compatível com tuberculose, de acordo com os critérios do SIF. Para o grupo 2 foram selecionadas 61 amostras julgadas como normais por inspetores do SIF, também das mesmas regiões. O tamanho amostral foi definido estatisticamente pelo programa EPIDAT 3.1, com um nível de confiança de $95 \%$, precisão de $3 \%$ e um efeito de desenho com fator de correção de 1.

Para ambos os grupos, imediatamente após a colheita, as amostras foram acondicionados em recipientes de boca larga, devidamente identificados, contendo solução fixadora aquosa de formol a $10 \%$ neutro e tamponado, na proporção de 8 a 10 vezes o volume do fixador em relação ao volume das amostras. Cortes de $5 \mu \mathrm{m}$ de espessura foram obtidos e corados pela técnica de hematoxilina e eosina (H\&E).

Devido à baixa sensibilidade relatada para a coloração de Ziehl-Neelsen, variando entre $15.4 \%$
(WATRELOT-VIRIEUX et al., 2006) e $33.9 \%$ (VARELLO et al., 2008) e a alta sensibilidade $(93,4 \%)$ e especificidade $(92,3 \%)$ para o diagnóstico histopatológico da tuberculose (VARELLO et al., 2008), optamos por não realizar a coloração especial neste estudo de forma rotineira. A técnica foi utilizada somente em casos duvidosos.

Utilizou-se estatística descritiva para a apresentação dos resultados.

\section{RESULTADOS}

A taxa de condenação total por tuberculose no estabelecimento em estudo foi de $0,006 \%$. Do total de animais abatidos no ano de 2006 (163.823), apenas 10 sofreram condenação total por tuberculose; 8 sofreram condenação parcial, sendo submetidos a tratamento por esterilização e sendo liberados ao consumo posteriormente. Os demais sofreram condenação parcial da área afetada, sendo o restante da carcaça liberada a consumo in natura, conforme legislação vigente (BRASIL, 1980).

Nos linfonodos do grupo 2 não foram observadas alterações microscópicas importantes. No grupo 1, dentre os linfonodos condenados pelos inspetores do SIF, 90,16\% apresentaram lesões microscópicas de tuberculose (Tabela 1), com necrose de caseificação central, composta por material eosinofílico homogêneo, debris celulares e quantidade variável de mineralização circundado por grande quantidade de macrófagos e células gigantes multinucleadas de Langhans, neutrófilos em alguns casos e tecido conjuntivo (Figura 1A).

Tabela 01. Lesões microscópicas encontradas no Grupo 1.

\begin{tabular}{lcc}
\hline Diagnóstico Histopatológico & $\mathrm{N}^{\circ}$ de amostras & $\%$ \\
\hline Granuloma tuberculóide & 55 & 90,16 \\
Granuloma actinomicóide & 3 & 4,92 \\
Armazenamento de estruturas cristalóides & 1 & 1,64 \\
Hiperplasia linfóide & 2 & 3,28 \\
\hline Total & 61 & 100 \\
\hline
\end{tabular}

No restante dos linfonodos condenados $(9,84 \%)$, observaram-se três casos de granuloma actinomicoide, dois de hiperplasia linfóide e um de acúmulo de estruturas cristalóides (Tabela 1).

Os granulomas actinomicóides estavam compostos centralmente por material filamentoso e bactérias Gram-positivas cocóides, não álcool-ácido resistentes, circundadas por infiltrado inflamatório de macrófagos, células epitelióides, células gigantes tipo Langhans, linfócitos, plasmócitos e quantidade variável de tecido fibroso - Reação de Splendore-
Hoeppli (Figura 1B).

Nos dois casos de hiperplasia linfóide, foi observado um aumento de tamanho acentuado e difuso do número de folículos linfóides na área cortical e hiperplasia da área paracortical moderada. As células linfocitárias apresentavam arquitetura normal e uniforme, núcleo eucromático e nucléolo evidente, indicando tratarem-se de células ativas e não neoplásicas. Em um caso foram encontrados depósitos de estruturas cristalóides dentro de macrófagos de aspecto espumoso, localizados 
principalmente nos seios medulares (Figura 1C).

\section{DISCUSSÃO}

Nas amostras analisadas, observou-se um bom índice de acerto no diagnóstico de tuberculose bovina por parte dos inspetores federais $(90,16 \%)$.
DEMELASH et al., (2009) relataram que o diagnóstico da tuberculose em abatedouro tem uma alta especificidade $(99,3 \%)$, valor um pouco superior ao encontrado neste estudo. A taxa de condenação total do estabelecimento foi baixa $(0,006 \%)$, dado provavelmente relacionado à origem dos animais: pecuária extensiva de corte.

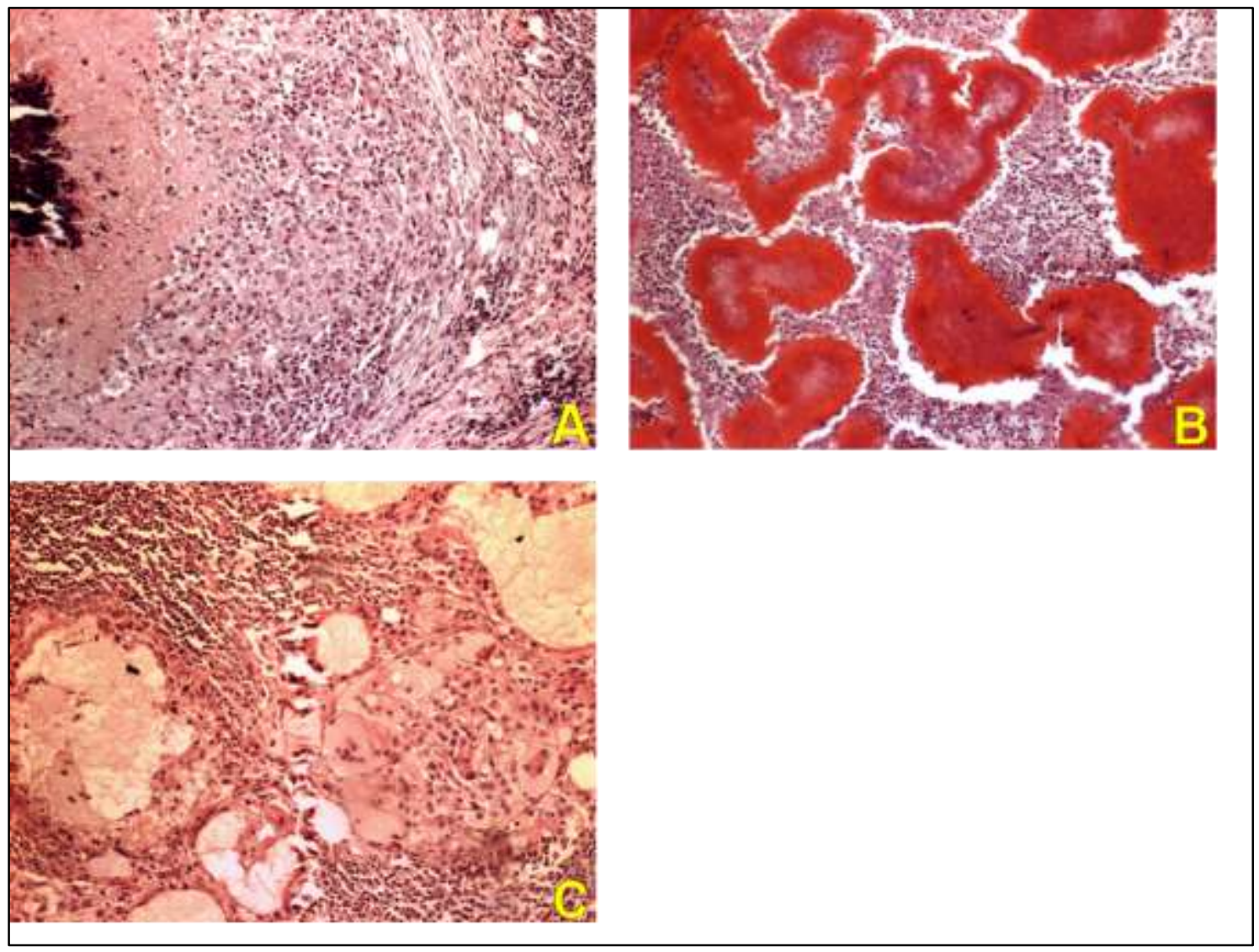

Figura 1. Linfonodo. A) Granuloma tuberculóide com calcificação central, circundado por necrose, macrófagos epitelióides, infiltrado inflamatório linfoplasmocitário e tecido fibroso. H\&E, Obj. 10x. B) Material de Splendore-Hoeppli circundado por necrose, debris celulares e infiltrado inflamatório de neutrófilos. H\&E, Obj. 10x. C) Grande quantidade de macrófagos espumosos contendo material cristalóide em seu interior. H\&E, Obj. 10x.

Das amostras coletadas, $9,84 \%$ não apresentaram lesão compatível com tuberculose, sendo, nesses casos, a condenação total ou parcial da carcaça desnecessária; entretanto, devido ao alto risco zoonótico da doença, é preferível condenar essas carcaças à liberar alguma positiva. Por outro lado, levando-se em conta a atual baixa lucratividade financeira da agropecuária nacional e o fato de que os animais condenados, ou parte deles, não serão pagos ao produtor, é necessário incrementar o nível de acerto dos inspetores, evitando-se, assim, perdas econômicas. Esse índice de erros poderia ser diminuído com uma análise mais aprofundada dos tecidos suspeitos, realizando-se a retenção da carcaça até o completo esclarecimento da etiologia.

A implantação de técnicas histológicas em cortes fixados por congelamento proporcionaria ao inspetor uma metodologia útil para diferenciar entre um processo tuberculoso de uma causa não infecciosa ou zoonótica. Essa técnica pode ser executada pelo próprio inspetor, não tem um custo operacional elevado, assim como não necessita de 
um processamento prolongado do material, podendo ser concluída em poucas horas. Representaria, ainda, uma forma de aprendizagem para o inspetor, possibilitando a realização de uma correlação entre a lesão macroscópica e a microscópica, corrigindo, dessa forma, futuros erros.

Nesta análise, devemos levar em conta, especialmente, que materiais condenados por tuberculose macroscopicamente apresentaram na microscopia uma hiperplasia linfóide (3,28\%), em que se observou aumento dos centros germinativos, sendo essa característica causada por qualquer simples reação inflamatória. Da mesma forma, as condenações por actinomicose $(4,92 \%)$ deveriam estar sujeitas a uma condenação parcial devido a seu caráter local, segundo o art. 158 do RIISPOA (BRASIL, 1980). O material condenado pelo SIF que apresentou microscopicamente acúmulo de ceróide, representado pela presença de cristais nos linfonodos reativos, não deveria ter sido condenado, pois o RIISPOA não faz menção a essa alteração.

Observou-se uma dificuldade de se diferenciar granuloma tuberculóide de granuloma actinomicóide, o qual foi identificado no estudo histopatológico em 4,92\% dos casos pela presença de drusas (Reação de Splendore-Hoeppli). Neste último, macroscopicamente, não se observa a presença de material caseoso, mas, sim, de pequenos pontos, grânulos de enxofre, de coloração amarelada e que não são vistos na tuberculose. Apesar de haver certas semelhanças macroscópicas entre as lesões de tuberculose e granuloma actinomicóide no exame microscópico, as diferenças entre as duas doenças são nítidas e não permitem confusão (ORTEGA et al., 2010). Neste sentido, recomendou-se um melhor treinamento dos inspetores para a correta diferenciação das duas patologias, aumentando-se, assim, o índice de acerto.

A hiperplasia linfóide geralmente indica um processo inflamatório ou neoplásico na região de drenagem correspondente a este grupo de linfonodos. Uma das possíveis causas dessa lesão macroscópica é a tuberculose, mas esta deve ser confirmada com o achado de outras lesões indicativas da patologia (ANDRADE et al., 1991). Nesse caso, uma avaliação histológica rápida poderia ser utilizada para descartar um processo neoplásico, o qual requereria condenação segundo o RIISPOA.

A baixa sensibilidade da coloração de ZiehlNeelsen para a detecção do Mycobacterium spp. (WATRELOT-VIRIEUX et al., 2006; VARELLO et al., 2008) está relacionada à utilização de formalina e parafina no processamento dos tecidos para diagnóstico (FUKUNAGA et al., 2002), comprometendo a sua utilização prática e impondo a análise macroscópica e histológica na rotina.

\section{CONCLUSÕES}

Conclui-se que o índice de acerto das condenações é satisfatório; entretanto, ele pode ser melhorado. Além disso, os agentes da inspeção confundem granuloma tuberculóide com granuloma actinomicóide. Sugere-se a utilização de técnicas diagnósticas complementares, especialmente nos casos suspeitos de tuberculose, como por exemplo, a análise histológica do material.

\section{REFERÊNCIAS}

ANDRADE, G.B.; RIET-CORREA, F.; MIELKE, P.V.; MÉNDEZ, M.C., SCHILD, A.L. Estudo histológico e isolamento de micobactérias de lesões similares a tuberculose no sul do Rio Grande do Sul. Pesquisa Veterinária Brasileira, v.11, n.3-4, p.81-96, 1991.

ARAÚJO, C.P.; LEITE, C.Q.F.; PRINCE K.A.; JORGE K.S.G.; OSÓRIO A.L.A.R. Mycobacterium bovis identification by a molecular method from post-mortem inspected cattle obtained in abattoirs of Mato Grosso do Sul, Brazil. Memórias do Instituto Oswaldo Cruz, v.100, n.7, p.749-752, 2005.

ASHFORD, D.A.; WHITNEY, E.; RAGHUNATHAN, P.; COSIVI, O. Epidemiology of selected mycobacteria that infect humans and other animals. Revue scientifique et technique (International Office of Epizootics), v.20, p.325-337, 2001.

BAPTISTA, F.; MOREIRA, E.C.; SANTOS, W.L.M.; NAVEDA, L.A.B. Prevalência da tuberculose em bovinos abatidos em Minas Gerais. Arquivo Brasileiro de Medicina Veterinária e Zootecnia, v.56, n.5, p.577-580, 2004.

BIET, F.; BOSCHIROLI, M.L.; THOREL, M.F.; GUILLOTEAU, L.A. Zoonotic aspects of Mycobacterium bovis and Mycobacterium aviumintracellulare Complex (MAC). Veterinary Research, v.36, p.411-436, 2005.

BRASIL. Regulamento da Inspeção Industrial e Sanitária de Produtos de Origem Animal - RIISPOA. Decreto no. 30.691, de 29/03/1952. Brasília, Ministério da Agricultura, 1980, 133p. Disponível em: <http://www.agricultura.gov.br/arq_editor/file/Aniamal/M ercadoInterno/Requisitos/RegulamentoInspecaoIndustrial. pdf >. Acessado em 10/12/2009.

BRASIL. Regulamento Técnico do Programa Nacional de Controle e Erradicação da Brucelose e Tuberculose - PNCEBT. Instrução Normativa No 2 de 10 de janeiro de 2001. Ministério da Agricultura, Pecuária e Abastecimento. Disponível em: <http://www.agricultura.gov.br/arq_editor/file/Aniamal/pr ograma nacional sanidade brucelose/Manual do PNCEBT - Original.pdf>. Acesso 09/12/2009. 
CEGIELSKI, J.P.; CHIN, D.P.; ESPINAL, M.A.; FRIEDEN, T.R.; RODRIGUEZ CRUZ, R.; TALBOT, E.A.; WEIL, D.E.; ZALESKIS, R.; RAVIGLIONE, M.C. The Global Tuberculosis Situation: Progress and Problems in the 20th Century, Prospects for the 21st Century. Infectious Disease Clinics of North America, v.16, n.1, p.58, 2002.

CURCIO, B.R.; GOMES, F.R.; MELO, D.M.; RAFFI, M.B.; RIET-CORREA, F.; LADEIRA, S.R.L. Isolamento de Arcanobacterium pyogenes de granuloma actinomicóide em bovino. Ciência Rural, v.32, n.5, p.885-889, 2002.

DE LA RUA-DOMENECH, R. Human Mycobacterium bovis infection in the United Kingdom: incidence, risks, control measures and review of the zoonotic aspects of bovine tuberculosis. Tuberculosis, v.86, p.77-109, 2006.

DEMELASH, B.; INANGOLET, F.; OLOYA, J.; ASSEGED, B.; BADASO, M.; YILKAL, A.; SKJERVE, E. Prevalence of Bovine Tuberculosis in Ethiopian slaughter cattle based on post-mortem examination. Tropical Animal Health and Production, v.41, p.755756,2009

EU, European Commission, Directorate of Health and Consumer Protection. Trends and sources of zoonotic agents in animals, feeding stuffs, food and man in the European Union and Norway in 2003. Disponível em: $<$ http://ec.europa.eu/food/food/biosafety/salmonella/001_c over_2003.pdf >. Acesso em 02/03/2009.

HERNADEZ, J.A. RENTERÍA EVANGELISTA, T.; LÓPEZ VALENCIA, G.; MONTAÑO HODGERS, M. An abattoir monitoring system for diagnosis of tuberculosis in cattle in Baja California, Mexico. Journal of the American Veterinary Medical Association, v.211, p.709-711, 1997.

KANEENE, J.B.; MILLER, R.A.; MEYER, R.M. Abattoir surveillance: The U.S. experience. Veterinary Microbiology, v.112, p.273-282, 2006.

MILIAN-SUAZO, F.; SALMAN, M.D.; RAMIREZ, C.; PAYEUR, J.B.; RHYAN, J.C.; SANTILLAN, M. Identification of tuberculosis in cattle slaughtered in Mexico. American Journal of Veterinary Research, v.61, n.1, p.86-89, 2000.

ORTEGA, J.; UZAL, F.A; WALKER, R.; KINDE, S. DIAB, S.S.; SHAHRIAR, F.; PAMMA, R.; EIGENHEER, A.; READ, D.H. Zygomycotic lymphadenitis in slaughtered feedlot cattle. Veterinary Pathology, v.47, n.1, p.108-115, 2010.
PAIXÃO, L.M.; GONTIJO, E.D. Perfil de casos de tuberculose notificados e fatores associados ao abandono, Belo Horizonte. Revista Saúde Pública, v.41, n.2, p.1-15, 2007.

POLLOCK, J.M.; WELSH, M.D.; MCNAIR, J. Immune responses in bovine tuberculosis: towards new strategies for the diagnosis and control of disease. Veterinary Immunology and Immunopathology, v.108, p.37-43, 2005.

RAVIGLIONE, M.C.; PIO, A. Evolution of WHO polices for tuberculosis control, 1948-2001. Lancet Infectious Diseases, v.359, p.775-780, 2002.

SALIHU, H.M.; NAIK, E.; O'BRIEN, W.F.; DAGNE, G.; RATARD, R.; MASON, T. Tuberculosis in North Carolina: Trends across Two Decades, 1980-1999. Emerging Infectious Diseases, v.7, n.3, p.570-574, 2001.

SOBORG, C.; SOBORG, B.; POUELSEN, S.; PALLISGAARD, G.; THYBO, S.; BAUER, J. Doubling of tuberculosis incidense in Greenland over an 8 years period (1990-1997). International Journal of Tuberculosis and Lung Disease, v.5, n.3, p.257-265, 2001.

TEKLUL, A.; ASSEGED, B.; YIMER, E.; GEBEYEHU, M.; WOLDESENBET. Z. Tuberculous lesions not detected by routine abattoir inspection: the experience of the Hossana municipal abattoir, southern Ethiopia. Revue scientifique et technique (International Office of Epizootics), v.23, n.3, p.957-64, 2004.

THOEN, C.; LOBUE, P.; DE CANTOR, I. The importance of Mycobacterium bovis as a zoonosis. Veterinary Microbiology, v.112, p.339-245, 2006.

VARELLO, K; PEZZOLATO, M.; MASCARINO, D.; INGRAVALLE, F.; CARAMELLI, M.; BOZZETTA, E. Comparison of histologic techniques for the diagnosis of bovine tuberculosis in the framework of eradication programs. Journal of Veterinary Diagnostic Investigation, v.20, p.164-169, 2008.

WATRELOT-VIRIEUX，D.; DREVON-GAILLOT，E.; TOUSSAINT, Y.; BELLI, P. Comparison of Three Diagnostic Detection Methods for Tuberculosis in French Cattle. Journal of Veterinary Medicine, v.53, p.321$325,2006$.

WHO. Implementing the STOP Strategy: a handbook for national tuberculosis control programmes. Geneve: World Health Organization. 2008. 198p. Disponível em: http://www.who.int/tb/publications/2008/who_htm_tb_20 08_401_eng.pdf. Acesso em julho de 2013. 